\title{
Pancreatic adenocarcinoma patients with localised chronic severe pancreatitis show an increased number of single beta cells, without alterations in fractional insulin area
}

\author{
M. Campbell-Thompson • L. R. Dixon • C. Wasserfall • \\ M. Monroe • J. M. McGuigan • D. Schatz • \\ J. M. Crawford • M. A. Atkinson
}

Received: 25 June 2008 / Accepted: 2 October 2008 / Published online: 11 November 2008

(C) Springer-Verlag 2008

\begin{abstract}
Aims/hypothesis Recent histological analysis of pancreases obtained from patients with long-standing type 1 diabetes identified chronic islet inflammation and limited evidence suggestive of beta cell replication. Studies in rodent models also suggest that beta cell replication can be induced by certain inflammatory cytokines and by gastrin. We therefore tested the hypothesis that beta cell replication is observed in non-autoimmune human pancreatic disorders in which localised inflammation or elevated gastrin levels are present. Methods Resected operative pancreatic specimens were obtained from patients diagnosed with primary adenocarcinoma (with or without chronic severe pancreatitis) or gastrinoma. Additional pancreatic tissue was obtained from autopsy control patients. Immunohistochemistry was used to assess fractional insulin area, beta cell number and replication rate and differentiation factors relevant to beta cell development.
\end{abstract}

Electronic supplementary material The online version of this article (doi:10.1007/s00125-008-1200-z) contains supplementary material, which is available to authorised users.

M. Campbell-Thompson $(\bowtie) \cdot$ L. R. Dixon · C. Wasserfall •

M. Monroe · J. M. Crawford · M. A. Atkinson

Department of Pathology, Immunology, and Laboratory Medicine,

University of Florida,

1600 SW Archer Road, P.O. Box 100275, Gainesville, FL 32610,

USA

e-mail: mct@ufl.edu

J. M. McGuigan

Department of Medicine, University of Florida,

Gainesville, FL, USA

D. Schatz

Department of Pediatrics, University of Florida,

Gainesville, FL, USA
Results Fractional insulin area was similar among groups. Patients with pancreatic adenocarcinoma and localised chronic severe pancreatitis displayed significant increases in the number of single beta cells, as well as increased beta cell replication rate and levels of neurogenic differentiation 1 in islets. Patients with gastrinoma demonstrated significant increases in the number of single beta cells, but the beta cell replication rate and islet differentiation factor levels were similar to those in the control group.

Conclusions/interpretation These findings indicate that chronic severe pancreatic inflammation can be associated with significant effects on beta cell number or replication rate, depending on the distribution of the cells. This information may prove useful for attempts seeking to design therapies aimed at inducing beta cell replication as a means of reversing diabetes.

Keywords Beta cells · Beta cell replication · Chronic pancreatitis · Gastrinoma · Islets of Langerhans .

Pancreatic adenocarcinoma

\author{
Abbreviations \\ AF-H\&E aldehyde fuchsin and haematoxylin and eosin \\ NEUROD1 neurogenic differentiation 1 \\ NEUROG3 neurogenin 3 \\ PDX1 pancreatic and duodenal homeobox protein 1
}

\section{Introduction}

A longstanding dogma regarding the pathogenesis of type 1 diabetes portends that, in the months to years following the initiation of insulin therapy, beta cell mass is irrevocably lost, with the pancreas becoming devoid of insulin- 
producing cells. This notion has, however, recently come under scrutiny following the development of the concept of beta cell regeneration [1]. Evidence supporting a loss of beta cell mass comes from many fields, including incretin pharmacology, stem cell biology, obesity, pregnancy and type 2 diabetes. However, the recent detection of insulinproducing cells within pancreases from patients with type 1 diabetes of intermediate to longstanding duration (i.e. 5 to 59 years) has been used by some to bolster the case for beta cell regeneration [2]. Specifically, this investigation indicated that pancreases from nearly $90 \%$ of these patients contained insulin-positive cells and that the presence of such cells was unrelated to disease duration.

At least three distinct mechanisms have been postulated to explain the proposed process of beta cell regeneration, and these include replication, neogenesis and transdifferentiation [3-5]. Based on studies of mice, some investigators have proposed that beta cell growth is entirely mediated by replication of existing beta cells [6]. Other investigations involving pancreases from type 1 diabetic patients support the concept of regeneration, although if true, the beta cell regenerative capacity appears to be lower in humans than in rodents [2]. Additional studies suggest that beta cells bud off from the pancreatic ducts, and this may be a process by which beta cells are derived following pancreatectomy [7]. While partial pancreatectomy in rodents rapidly induces beta cell regeneration, this process was not observed to occur in patients with pancreatic resections involving more than $50 \%$ of the initial pancreatic mass [8]. Evidence for beta cell transdifferentiation has been observed both in vitro and in vivo in animal studies $[9,10]$, but it remains controversial as to whether this occurs in humans [11].

A potential role for gastrin in beta cell regeneration has been indicated by studies showing increased beta cell mass in mice following administration of this factor, especially when co-administered with epidermal growth factor [12]. Additionally, treatment of NOD mice with a combination of gastrin and epidermal growth factor increased insulin content eightfold [13]. In humans, hypergastrinaemia is observed in settings of primary gastrinoma (Zollinger-Ellison syndrome) or secondary to pharmacologically induced chronic acid suppression [14]. However, a recent study analysing surgical samples from four gastrinoma patients showed no evidence of increased beta cell replication [15]. Increased beta cell replication has been noted in rodent studies involving overproduction of $\gamma$-interferon, transforming growth factor- $\beta$, IL-1 $\beta$ and other cytokines [16-19]. This finding has recently been supported by a study in which pancreatic specimens obtained from patients with chronic pancreatitis showed evidence of increased numbers of insulin-positive cells and cells containing transcriptional markers of endocrine origin (i.e. pancreatic and duodenal homeobox protein 1 [PDX1]) in ducts [20]. This study was, however, limited by the fact that the control group consisted of autopsy specimens from children and young adults and that the extent and the nature of chronic pancreatitis was not provided.

With this continued uncertainty about conditions under which beta cell regeneration may occur in the human, we elected to examine the uninvolved regions of pancreases surgically removed from patients with pancreatic adenocarcinoma. In these samples, the presence or absence of localised inflammation may give an indication of whether inflammation can stimulate changes in beta cell mass. To also allow for inter-hospital comparisons with existing related studies [20, 21], we also included autopsy-based specimens from patients without clinical evidence of pancreatic disease as normal controls. Histopathological assessment of the severity of chronic pancreatitis was performed, as was assessment of morphological markers of beta cell replication and cell lineage. Determination of the markers included studies characterising the levels of PDX1, neurogenic differentiation 1 (NEUROD1) and neurogenin 3 (NEUROG3), as these transcription factors are intimately involved in the differentiation of precursor endocrine cells into beta cells [22, 23]. Since insulin-positive cells were not restricted solely to islets (they were also observed within small clusters or as single cells), we sought to quantify the number and replication rate of all insulin-positive cells.

\section{Methods}

Patients A total of 25 patients were included in this study (Table 1). Patients were first selected by a retrospective search of the clinical database of the University of Florida and Shands Hospital (Gainesville, FL, USA) over the last 20 years for patients treated by pancreatic resection who had a diagnosis of primary pancreatic adenocarcinoma or pancreatic gastrin-secreting tumour (gastrinoma). Patients with a clinical history of symptomatic pancreatitis were excluded from selection, since the goal of this study was to examine pancreatic tissue damaged by localised mass lesions, rather than pancreatitis arising in the setting of systemic conditions (e.g. alcoholism). Patients with gastrinoma had no clinical diagnosis other than a primary pancreatic tumour. From an initial search yielding 33 cases, 25 patients were subsequently found to have one or more uninvolved tissue blocks available for further study. The uninvolved tissue blocks were selected by review of the final pathology findings for an ancillary pathological diagnosis of no pancreatitis or chronic severe pancreatitis (samples with $>20 \%$ of the acinar area infiltrated with mononuclear cells and fibrosis). Of the nine cases listed as having no pancreatitis on the pathology report, four were subsequently deemed to have incidental chronic focal, mild pancreatitis following histopathology review (samples with $<5 \%$ of 
Table 1 Study patients and demographics

\begin{tabular}{|c|c|c|c|c|}
\hline Clinical diagnosis & Histopathology & $\operatorname{Sex}^{\mathrm{a}}$ & Age (years) & Ethnicity $^{\mathrm{b}}$ \\
\hline Autopsy control & No pancreatitis & $\mathrm{F}$ & 20 & $\mathrm{C}$ \\
\hline Autopsy control & No pancreatitis & $\mathrm{F}$ & 27 & $\mathrm{C}$ \\
\hline Autopsy control & No pancreatitis & $\mathrm{F}$ & 57 & $\mathrm{C}$ \\
\hline Autopsy control & No pancreatitis & $\mathrm{F}$ & 71 & $\mathrm{C}$ \\
\hline Autopsy control & No pancreatitis & M & 55 & $\mathrm{C}$ \\
\hline Pancreatic adenocarcinoma & No pancreatitis & $\mathrm{F}$ & 36 & $\mathrm{~B}$ \\
\hline Pancreatic adenocarcinoma & No pancreatitis & $\mathrm{F}$ & 47 & $\mathrm{C}$ \\
\hline Pancreatic adenocarcinoma & No pancreatitis & $\mathrm{F}$ & 69 & $\mathrm{C}$ \\
\hline Pancreatic adenocarcinoma & No pancreatitis & M & 58 & - \\
\hline Pancreatic adenocarcinoma & No pancreatitis & M & 77 & $\mathrm{C}$ \\
\hline Pancreatic adenocarcinoma & No pancreatitis & M & 82 & - \\
\hline Pancreatic adenocarcinoma & Mild pancreatitis & $\mathrm{F}$ & 24 & $\mathrm{~B}$ \\
\hline Pancreatic adenocarcinoma & Mild pancreatitis & $\mathrm{F}$ & 48 & $\mathrm{C}$ \\
\hline Pancreatic adenocarcinoma & Mild pancreatitis & $\mathrm{F}$ & 48 & $\mathrm{C}$ \\
\hline Pancreatic adenocarcinoma & Mild pancreatitis & $\mathrm{F}$ & 62 & $\mathrm{C}$ \\
\hline Pancreatic adenocarcinoma & Severe pancreatitis & $\mathrm{F}$ & 76 & - \\
\hline Pancreatic adenocarcinoma & Severe pancreatitis & M & 43 & $\mathrm{C}$ \\
\hline Pancreatic adenocarcinoma & Severe pancreatitis & M & 54 & $\mathrm{C}$ \\
\hline Pancreatic adenocarcinoma & Severe pancreatitis & M & 55 & $\mathrm{H}$ \\
\hline Hypergastrinaemia & No pancreatitis & $\mathrm{F}$ & 21 & $\mathrm{C}$ \\
\hline Hypergastrinaemia & No pancreatitis & $\mathrm{F}$ & 34 & $\mathrm{C}$ \\
\hline Hypergastrinaemia & No pancreatitis & $\mathrm{F}$ & 48 & $\mathrm{C}$ \\
\hline Hypergastrinaemia & No pancreatitis & $\mathrm{F}$ & 53 & $\mathrm{C}$ \\
\hline Hypergastrinaemia & No pancreatitis & $\mathrm{F}$ & 70 & $\mathrm{C}$ \\
\hline Hypergastrinaemia & No pancreatitis & M & 79 & $\mathrm{C}$ \\
\hline
\end{tabular}

${ }^{\mathrm{a}} \mathrm{F}$, female; M, male

${ }^{\mathrm{b}}$ B, African American; H, Hispanic; C, Caucasian; -, not available

acinar tissue infiltrated with mononuclear cells and replaced by fibrosis). Ultimately, 14 patients with pancreatic adenocarcinoma were selected and were subsequently stratified based on the absence $(n=6)$ or presence of chronic mild $(n=4)$ or severe $(n=4)$ pancreatitis in the uninvolved tissue block (hereafter referred to as no, mild and severe pancreatitis groups). Six patients with preoperative and final pathological diagnosis of intrapancreatic gastrinomas, confirmed by gastrin immunohistochemistry, had uninvolved sample blocks available for further evaluation. In addition, tissue samples were collected at autopsy from five patients (hereafter referred to as autopsy control) with no clinical history of diabetes or pancreatic disease, and whose pancreases were normal by histological examination. Exclusion criteria for all sample block selections were: $>5 \%$ tumour infiltration in the uninvolved sample, acute pancreatitis or $>5 \%$ acinar autolysis. The study protocol for retrospective pathology report review and analyses of beta cells was approved by the University of Florida Institutional Review Board as an exempt protocol with waiver of informed consent.

Pancreatic histology Paraffin blocks were obtained from the Shands Hospital archive. The standard histological procedure was fixation in $10 \%$ zinc formalin followed by paraffin embedding. Paraffin blocks were serially sectioned $(4 \mu \mathrm{m})$ and sections were stained with aldehyde fuchsin and haematoxylin and eosin (AF-H\&E) and then immunolocalisation studies were conducted. AF-H\&E-stained slides were reviewed by two investigators (L. R. Dixon, M. CampbellThompson) to confirm histopathological findings and exclusion criteria.

Immunohistochemistry and immunofluorescence Immunolocalisation was performed with primary and secondary antibodies (Electronic supplementary material Tables 1 and 2) using previously described detection methods [24]. In brief, deparaffinised sections were incubated in 3\% (vol./vol.) hydrogen peroxide in methanol for $10 \mathrm{~min}$ to block endogenous peroxidase activity. Antigen retrieval was performed, when required, by heating samples at $95^{\circ} \mathrm{C}$ for $25 \mathrm{~min}$ in citrate buffer, pH 6.0 (Dako, Carpentina, CA, USA). Sections were incubated in $10 \%$ goat or rabbit serum and endogenous avidin-biotin binding was blocked (Avidin Biotin Blocking Kit; Vector Labs, Burlingame, CA, USA) when required. The primary antibody was incubated for $1 \mathrm{~h}$ at room temperature or overnight at $4{ }^{\circ} \mathrm{C}$. Following extensive washing, the secondary antibody was applied and the antibody complex detected using a Vectastain ABC kit 
with 3,3-diaminobenzidine (DAB) chromagen (Vector Labs) or the MACH2 polymer system used with Vulcan Fast Red chromagen (Biocare Medical, Concord, CA, USA). Double staining was performed using sequential application and detection of each primary antibody. Sections were lightly counterstained in haematoxylin and mounted. Slides were photographed with a Zeiss Axioskop and Axiocam HR colour camera (Carl Zeiss, Thornwood, NY, USA) or scanned with a ScanScope CS imaging system (Aperio, Vista, CA, USA).

For double-staining immunofluorescence, Ki-67 was detected using Alexa Fluor 488-conjugated secondary antibodies (Invitrogen Molecular Probes, Carlsbad, CA, USA) followed by insulin detection using an Alexa Fluor 594conjugated secondary antibody. Nuclei were stained with mounting media containing 4,6-diamidio-2-phenylindole (DAPI) (Vectashield; Vector Labs). Sections were photographed using the Zeiss Axioskop with a dual fluorescein isothiocyanate (FITC)/Texas Red filter for visualisation of both fluorochromes using Axiovision 4.0 software. The same exposure settings were used for all samples.

Incubation conditions for primary antibodies were optimised using control human tissue samples and testing several enzymatic and heat-based antigen retrieval methods. A positive and negative control sample was included in each assay run to allow interassay comparisons. Negative controls included substitution of the primary antibody with $\mathrm{IgG}$ from the host species that was used to generate the primary antibody and by incubation with primary antibody dilution buffer alone.

Morphometric analysis Fractional insulin area was calculated as the ratio of insulin immunoreactive area/total pancreatic area per field of view (five to ten non-overlapping acinar regions; 20× objective lens) using Metamorph 6.0 software (Molecular Devices, Sunnyvale, CA, USA) for immunofluorescence. Insulin-positive cells were identified by red fluorescence, and cells of all colours were counted for total acinar tissue. Fractional insulin area was also determined on whole slide scans using the positive pixel count algorithm in ImageScope 9.0 (Aperio). The pen tool was used to exclude regions of fibrosis in pancreatic tumour samples.

To quantify beta cells with Ki-67 co-localisation, five to ten non-overlapping fields of view ( $20 \times$ objective lens) were photographed using a dual FITC/Texas Red filter set. Insulin-positive cells in each field of view were manually counted using the image zoom function on a 21 inch video monitor to aid discrimination. Ki-67-positive beta cell nuclei were counted and their distribution (islets, clusters [two to six positive cells] or single cells) recorded. Total beta cell number per field of view was calculated from a sum of islet, cluster and single cell counts. Ki-67-positive beta cells were defined as cells with a Ki-67-positive nucleus of similar size to other beta cell nuclei within an insulin-positive cytoplasm.
Analyses were performed by staff blinded to patient tumour group.

Immunohistochemistry scoring PDX1, NEUROD1 and NEUROG3 immunopositivity in the nuclei of cells in islets, ductular epithelium and acinar regions were scored. Each patient sample had at least five medium-power field of views (40× objective lens) randomly selected that contained islets and ducts, each with a minimum of 25 cells. The percentage of stained nuclei was estimated. For acinar cells, five highpower fields of view $(60 \times$ objective lens) were randomly selected and the overall percentage of nuclear staining was estimated.

Statistical analysis Data are shown as mean \pm SEM. Comparisons between patient groups were carried out by singlefactor ANOVA and post hoc Student's $t$ test (two-tailed). A $p$ value of less than 0.05 was considered statistically significant. A two-sample test using average values for the number of single beta cells was performed using the statistical power calculator (Researcher's tool kit; DSS Research, Fort Worth, TX, USA).

\section{Results}

Routine histopathological examination of pancreases showed no significant findings in normal autopsy controls or patients with gastrinoma, other than mild focal fibrosis in the latter. Samples of pancreases from patients with adenocarcinoma and chronic pancreatitis had varying degrees of perilobular fibrosis, ductular proliferation or hyperplasia, and acinar atrophy that was heterogeneous between lobules (Fig. 1). Islet inflammation (insulitis) was not present in any sample as indicated by the lack of several mononuclear cells surrounding or within the islet by AF$\mathrm{H} \& \mathrm{E}$ staining. Insulin staining by acinar region was variable within patients and was recognised in islets of varying sizes, small clusters and single cells (Figs 1,2). Insulin-positive cells were infrequently observed within the ductular epithelium (immunostained with cytokeratin 7) in all groups (Fig. 2).

As previous studies have suggested that beta cell mass may be influenced by a variety of pathological conditions, including those providing the focus for this report, we considered it important to address the issue of fractional insulin area. Fractional insulin area provides an assessment of the proportion of pancreatic cells that are insulin-positive cells, as an indicator of beta cell mass [21, 25-27]. Using this well-accepted method of analysis, very limited differences in fractional insulin area were noted amongst the five study groups using immunohistochemistry $(1.4 \pm 0.1 \%$ 


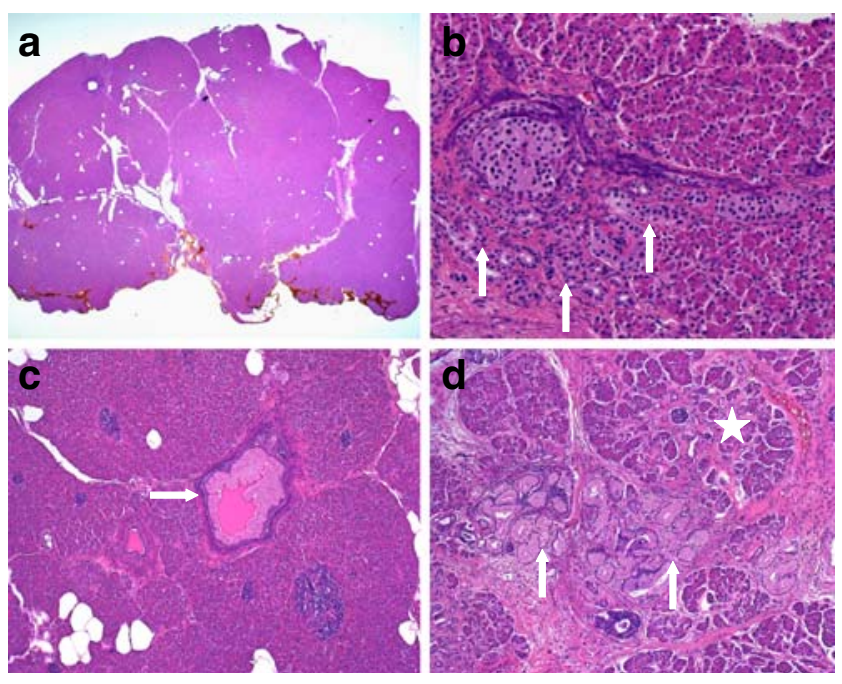

Fig. 1 Pancreatic histopathology in uninvolved regions from patients with primary adenocarcinoma. Paraffin sections were stained with AFH\&E for identification of insulin-positive beta cells (dark purple). a Section from a patient with adenocarcinoma and no pancreatitis (original magnification: $\times 1.25$ ). The red dye at lower margin indicates orientation towards the adenocarcinoma. Mild intralobular adipose tissue is present. b Focal ductular proliferation in a patient with no pancreatitis. Cross-sections of ducts are visible (arrows), in addition to a large group of cells that are not stained by AF-H\&E. Elastic fibres in a large blood vessel are stained dark purple with AF-H\&E. c Pancreatic morphology in a patient with chronic mild pancreatitis. Islets of varying sizes are observed in different lobules. Focal ductular hyperplasia (arrow) is observed in a large duct with multifocal mild adipose tissue (clear spaces) present in the acinar regions. d Pancreatic morphology in a patient with chronic severe pancreatitis. Focal, mild acinar atrophy was observed (white star) with focal, moderate ductular proliferation and hyperplasia (arrows)

autopsy control, $1.1 \pm 0.1 \%$ no pancreatitis, $2.0 \pm 0.2 \%$ mild pancreatitis, $1.8 \pm 0.7 \%$ severe pancreatitis, $1.5 \pm 0.2 \%$ gastrinoma). Indeed, the only comparison within the five study groups reaching statistical significance was that of patients with no pancreatitis vs those with severe pancreatitis, using the immunofluorescence field of view measurements, where a significantly increased fractional area was noted in the latter group $(3.2 \pm 0.5 \%$ vs $5.9 \pm$ $1.4 \%$, respectively, $p<0.05$ ). Fractional insulin area in the samples from autopsy patients was $4.1 \pm 0.6 \%$, which was slightly lower than that from patients with mild pancreatitis $(5.2 \pm 0.9 \%)$ or hypergastrinaemia $(5.3 \pm 1.0 \%)$.

The number of insulin-positive cells in islets, clusters or as single cells was quantified and the total number of insulin-positive cells calculated (Fig. 3a). These data represent a total of 20,693 beta cell counts (i.e. 4,451 autopsy control, 3,407 no pancreatitis, 3,731 mild pancreatitis, 4,122 severe pancreatitis, 4,982 gastrinoma). Similar to the fractional insulin area data, total beta cell number was highest in the severe pancreatitis group, although these data were also the most variable $(209 \pm 89$; Fig. 3a). The no pancreatitis group had the lowest total beta cell number

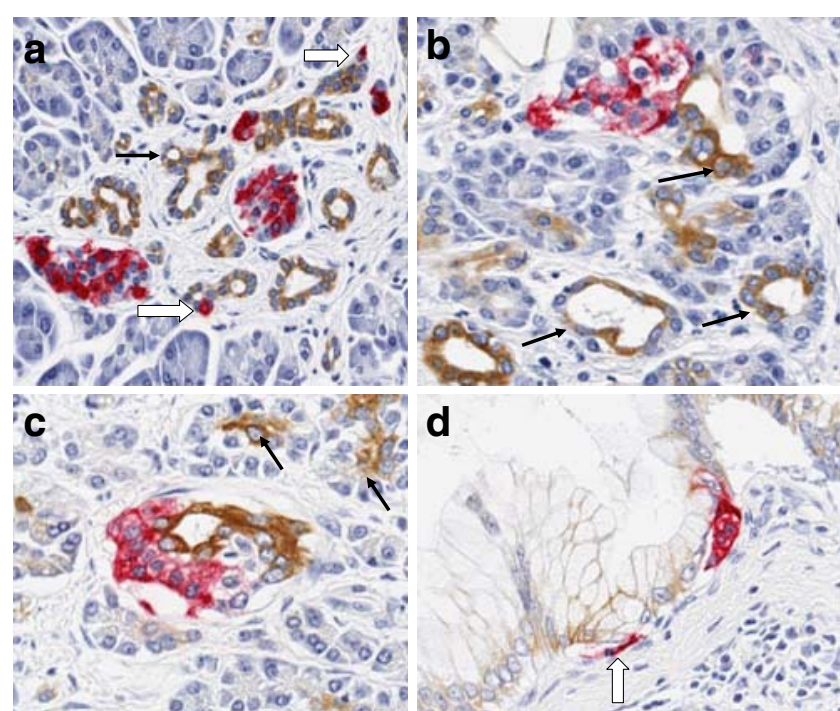

Fig. 2 Pancreatic immunohistochemistry for pancreatic ductular epithelium and insulin from adenocarcinoma patients with no or mild pancreatitis. Pancreatic sections were double-stained for cytokeratin 7 (CK7, brown) and insulin (red) as described in the Methods. CK7 immunopositivity was found in ducts and centroacinar cells (a-c, black arrows) adjacent to unstained acinar cells. Insulin-positive cells were identified in close proximity to, or within, ductular epithelium in all patient groups. Insulin-positive cells were found as single cells (a, d, white arrows) or clusters (a-d) and were only rarely observed in ducts with hyperplasia (d)

$(101 \pm 13)$, which was significantly lower than that in the autopsy control $(178 \pm 35, p=0.053)$, mild pancreatitis ( $173 \pm$ $26, p=0.027)$ and gastrinoma $(200 \pm 45, p=0.046)$ groups (Fig. 3a). Islet beta cell number was similar for all groups except the no pancreatitis group, which had a significantly lower number than the mild pancreatitis group ( $92 \pm 13$ vs $157 \pm 20$, respectively, $p=0.020$; Fig. $3 b$ ). These two groups showed the lowest variability in beta cell count. The number of beta cells in clusters was similar among autopsy controls $(15 \pm 4)$ and patients with no $(6 \pm 1)$ or mild pancreatitis $(10 \pm 5$; Fig. 3c). The number in these three groups was lower than that in the severe pancreatitis group $(45 \pm 15, p=0.051$ vs autopsy controls, $p=0.008$ vs no pancreatitis, $p=0.057$ vs mild pancreatitis). Furthermore, similar to the severe pancreatitis group, the gastrinoma patients had a significantly increased number of beta cells in clusters compared with the no pancreatitis group $(27 \pm 6, p=0.005)$. Strikingly, the largest increase in beta cell count in the severe pancreatitis and gastrinoma groups was observed for single beta cells, with values $(21.3 \pm 2.2$ and $19.6 \pm 5.1$, respectively) significantly higher $(p<0.005)$ than those in the control $(3.6 \pm 0.9)$ and no $(2.4 \pm 0.4)$ or mild $(5.2 \pm 2.5)$ pancreatitis study groups (statistical power $99 \%, \alpha=0.05, \beta=0.80$; Fig. $3 d$ ).

For assessment of beta cell replication, Ki-67 nuclear staining of insulin-positive cells was used as an index of the cellular proliferation rate. Of the aforementioned 20,693 beta cells analysed, 86 beta cells had Ki-67-positive nuclei 


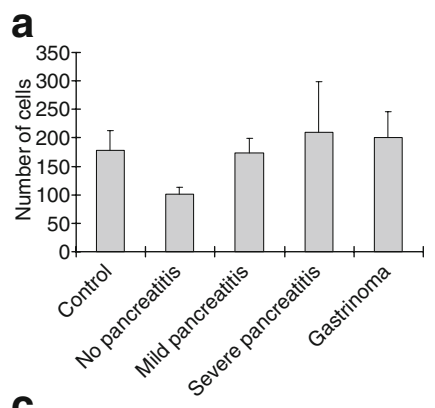

C

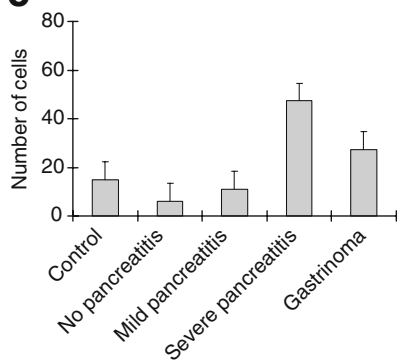

d
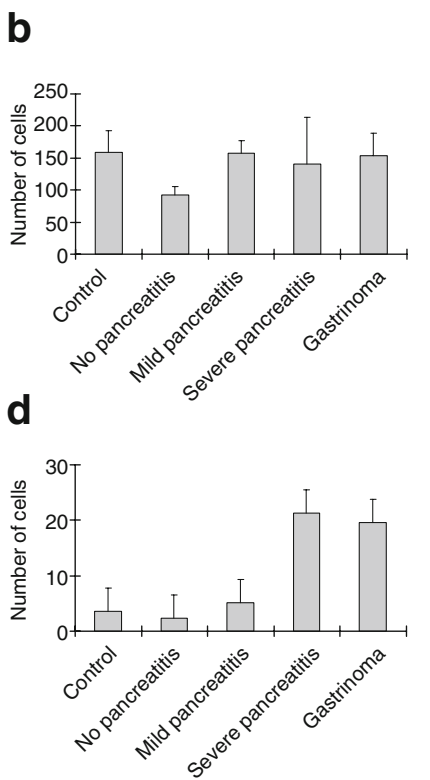

Fig. 3 Total number of beta cells (a) and number of beta cells in islets (b), clusters (c) and as single cells (d) in the different patient groups. Beta cells were identified by anti-insulin immunofluorescence, images acquired using a $20 \times$ objective lens, and the number of positive cells counted per field of view. a Patients with mild pancreatitis and gastrinoma had a significantly higher total number of beta cells compared with patients with no pancreatitis $(p=0.05)$. b Beta cell numbers within islets were lowest in the no pancreatitis group when compared with patients with mild pancreatitis $(p=0.02)$. $\mathbf{c}$ The number of beta cells in clusters were significantly higher in patients with severe pancreatitis and gastrinoma than in patients with no pancreatitis $(p<0.01)$. d Patients with severe pancreatitis and gastrinoma had a significantly higher number of single beta cells compared with the control and both no and mild pancreatitis groups $(p<0.005)$

$(0.42 \%$ overall). Beta cell proliferation rate, expressed as either the percentage of total or islet beta cells with Ki-67 nuclear staining, was significantly increased $(p<0.005)$ in the severe pancreatitis group compared with all other groups (Fig. 4). The beta cell proliferation rate within clusters was similar for all groups $(0.2 \pm 0.1 \%$ overall; Fig. 4). Single beta cells showed highly variable proliferation rates; the rate was highest in the severe pancreatitis group $(3.4 \pm 1.7 \%)$ but there were no significant differences between groups (Fig. 4). As age has been reported to influence the beta cell replication rate [21], the ages of the different patient groups were analysed for statistical differences; none were found (autopsy control $43 \pm 8$ years [ $n=5]$, no pancreatitis $57 \pm 7$ years [ $n=6]$, mild pancreatitis $46 \pm 8$ years $[n=4]$, severe pancreatitis $62 \pm 7$ years $[n=4]$, gastrinoma $44 \pm 7$ years $[n=6])$.

Pancreas samples from all study groups were examined for levels of three transcription factors (PDX1, NEUROD1 and NEUROG3) associated with the differentiation of pancreatic endocrine precursors into adult beta cells. Surprisingly, transcription factor levels in islets from the autopsy

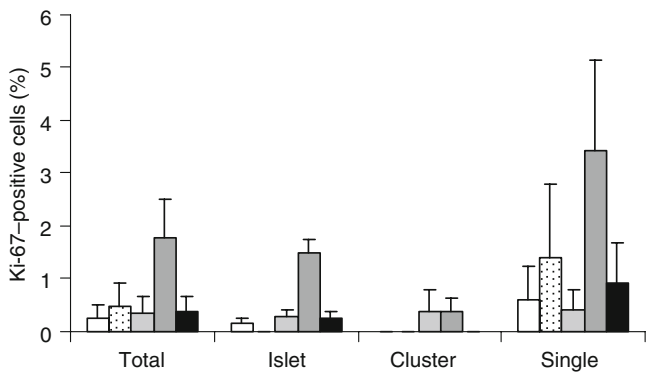

Fig. 4 Beta cell proliferation rates determined by Ki-67 levels. The proportion of $\mathrm{Ki}-67$-positive beta cells are shown for each group expressed as total cells or beta cells within islets, clusters or as single cells. Despite variability, the severe pancreatitis group showed a significantly higher proportion of total Ki-67-positive beta cells $(p<0.005)$ compared with all other groups. The average count of Ki67 -positive beta cells in islets was also significantly higher in the severe pancreatitis patients than in all other groups $(p<0.005)$. Ki-67 positivity was most variable within single beta cells. Control, white bars; no pancreatitis, stippled bars; mild pancreatitis, light grey bars; severe pancreatitis, dark grey bars; gastrinoma, black bars

control samples were lower than those in all other groups (Fig. 5d). These data suggest that pancreatic sample harvesting post-mortem could lead to altered levels of these transcription factors.
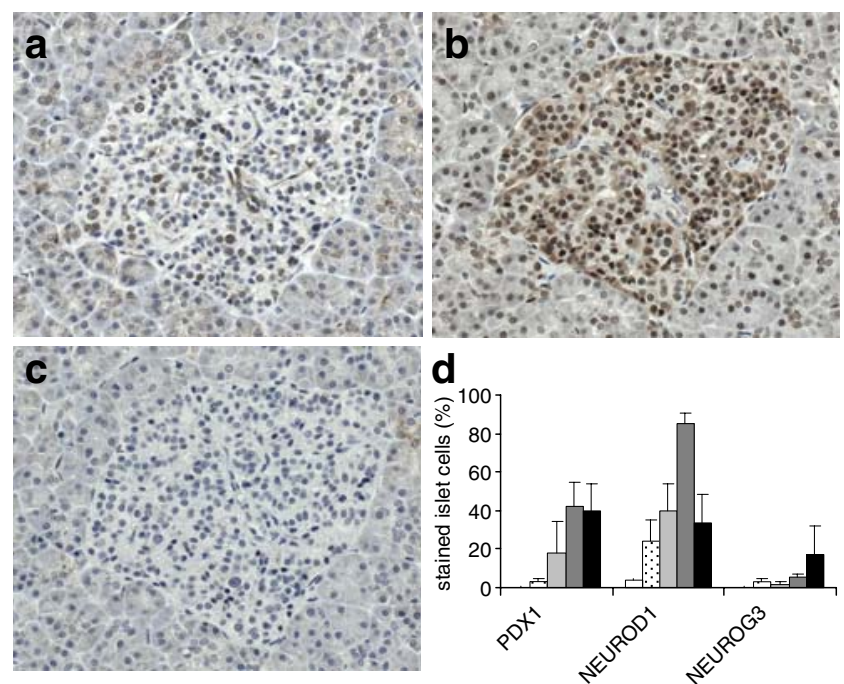

Fig. 5 PDX1, NEUROD1 and NEUROG3 levels in pancreatic islets. Representative islet images showing immunostaining for PDX1 (a), NEUROD1 (b) and NEUROG3 (c) in serial sections from a patient with mild pancreatitis. d Semi-quantitative analysis of percentage of nuclear staining for PDX1, NEUROD1 and NEUROG3 in islets. The level of PDX1 was significantly higher in the severe pancreatitis and gastrinoma groups than in the autopsy control and no pancreatitis groups $(p<0.03)$. The level of NEUROD1 was significantly higher in the severe pancreatitis group than in all other groups $(p<0.02)$. Patients with either mild pancreatitis or gastrinoma also showed intermediate NEUROD1 levels compared with controls $(p<0.05)$. NEUROG3 levels were lower than PDX1 or NEUROD1 and no significant differences were observed between groups. Control, white bars; no pancreatitis, stippled bars; mild pancreatitis, light grey bars; severe pancreatitis, dark grey bars; gastrinoma, black bars 
PDX1 immunoreactivity was found predominantly in islet cells (Fig. 5a), with low levels observed in pancreatic ducts and acinar cells. Islet levels of PDX1 were significantly higher in both the severe pancreatitis $(42 \pm 13 \%, p=0.009)$ and gastrinoma $(40 \pm 14 \%, p=0.02)$ groups than in the no pancreatitis group ( $3 \pm 2 \%$; Fig. 5 d). There was virtually no PDX1 present in islet cells of autopsy control patients $(0.2 \pm 0 \%$; Fig. 5 d). Interestingly, patients with mild pancreatitis had intermediate, yet highly variable, islet levels of PDX1 $(18 \% \pm 10 \%)$.

In contrast to the largely limited islet levels of PDX1, NEUROD1 was observed in islets (Fig. 5b) as well as in ducts and acinar cells. The proportion of NEUROD1positive islet cells was significantly higher in patients with severe pancreatitis $(85 \% \pm 6 \%, p<0.02)$ than in all other patients (Fig. 5d). Islet levels of NEUROD1 were moder-

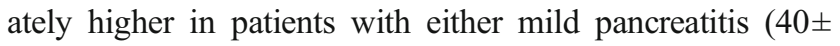
$14 \%)$ or gastrinoma $(34 \pm 14 \%)$ than in patients without pancreatitis (24 $\pm 11 \%$; Fig. $5 \mathrm{~d})$. Levels of NEUROD1 in ducts and acinar cells were higher in both the severe pancreatitis and gastrinoma groups than in the no or mild pancreatitis groups, but variability precluded demonstration of significant differences (data not shown).

As expected for adult tissues, NEUROG3 levels were lower than PDX1 and NEUROD1 levels (Fig. 5c,d). In addition, the gastrinoma group had the highest islet NEUROG3 levels $(18 \pm 14 \%)$ of all the study groups, although there were no statistically significant differences between any of the groups (Fig. 5d).

\section{Discussion}

Studies on the regulation of beta cell mass indicate that these cells show a remarkable degree of plasticity in response to a variety of experimental and physiological conditions, ranging from pregnancy to obesity. As noted earlier, there are data suggesting that pancreatic disorders associated with elevations in localised cytokine production could increase beta cell mass. In theory, cytokines released from the inflammatory cells or the tumour itself could induce beta cell replication [19]. Intriguing new data show that immune cell infiltration in islets also triggers beta cell replication [28]. Gastrin is a potent growth factor for the entire gastrointestinal tract and is produced in fetal islet cells $[29,30]$. Excessive serum gastrin levels could produce profound growth effects on cell types expressing gastrin receptors, including pancreatic ductular epithelium and acinar cells $[25,31]$. To address our hypothesis that beta cell replication would be observed in non-autoimmune human pancreatic disorders with chronic pancreatitis and localised inflammation or elevated gastrin levels, we performed a series of studies assessing the fractional insulin area as a marker of beta cell mass, followed by detailed analysis of beta cell numbers and replication rates with three different pancreatic distribution patterns.

Marked heterogeneity in the fractional insulin area of pancreas specimens from autopsy patients has been noted, with variance of up to 80-fold in the same patient [32]. Our study corroborates these findings and shows a trend for patients with no pancreatitis to show the lowest fractional insulin area. This trend was also observed using total or islet beta cell counts. Thus, our data, despite being obtained from a relatively small sample set, are consistent with others who report that patients with pancreatic adenocarcinoma can show decreased beta cell numbers in islets [33, 34]. Since these differences were not significantly different from autopsy controls, these patients would not be expected to have alterations in blood glucose, although we were not able to address this, owing to the nature of our institutional review board approval. Of note, fractional insulin area and total and islet beta cell counts in patients with chronic pancreatitis, whether mild or severe, were comparable to those in autopsy controls and gastrinoma patients.

Importantly, our studies suggest that analysis of beta cell distribution provides a more accurate reflection of the dynamics of beta cell homeostasis than does fractional insulin area. That is to say, summation of all the beta cells present within well-formed islets or as isolated cells or clusters is necessary for assessment of total beta cell mass. Indeed, our data indicate that beta cells present as single cells show significant plasticity in patients with severe pancreatitis and in gastrinoma patients. While exocrine tissue area can be expected to be reduced in severe pancreatitis, our data showing that both these patient groups had an increased number of single beta cells would tend to argue that single beta cells were not more obvious in severe pancreatitis samples.

Prevailing thought holds that beta cell replication in the adult pancreas is rare. Indeed, carefully sorted human beta cells from islet preparations failed to replicate in vitro, in marked contrast to beta cells isolated from rat islets [35]. However, recent reports suggest that the capacity for lifelong beta cell replication exists in humans [21, 28, 32, 36]. While such data in humans are limited, in autopsy samples it was shown that $0.04 \%$ of human beta cells produce Ki-67 [32]. Furthermore, a low beta cell replication rate $(0.13 \pm 0.08 \%)$ has been reported in other autopsy samples using $\mathrm{Ki}-67 \mathrm{co}-$ localisation [36]. Similar to these reports, we consistently found that only a low proportion of the islet beta cells were Ki-67-positive $(\sim 0.3 \%)$, except when severe pancreatitis $(1.5 \pm 0.2 \%)$ was present. Although significantly different from the proportion in samples from other groups, as expected, this low proportion did not alter fractional insulin area.

While the current study is limited by the small number of cases and the expected variability associated with cell counting methodologies, our study supports a recent case 
report that showed an increased islet beta cell replication rate in an 89-year-old patient with recent-onset type 1 diabetes and pancreatic adenocarcinoma [32]. Taken together, these studies show the potential for beta cell replication to continue during adulthood.

As suggested by many investigators, the absence of an increase in periductal islets or intraductal insulin-positive cells implies that beta cell regeneration in humans is predominately accomplished by beta cell replication [21]. Islet ductal complexes and isolated insulin-positive cells in ducts have also been reported in pancreases obtained from autopsy specimens and organ donors [21,37]. Similarly, we observed insulin-positive cells in ducts from all patient groups. While the increase in the number of single beta cells in both the severe pancreatitis group and the gastrinoma group was not associated with a simultaneous increase in the number of insulin-positive cells in ductal complexes or ducts, the exact origin of the single beta cells remains unknown.

We elected to characterise levels of beta cell differentiation factors within islets, ducts and acinar regions. During fetal pancreatic endocrine development, PDX1 regulates the early pancreatic epithelium, permitting its proliferation, branching and subsequent differentiation [38]. In the current study, PDX1 levels were moderately increased in islets from both severe pancreatitis and gastrinoma samples but were not found in ducts. Our data are in contrast to those showing ductal levels of PDX1 in chronic pancreatitis [20]; however, differences between the two studies with respect to the primary antibodies used and in the staging of pancreatitis could account for this discrepancy. NEUROD1 and NEUROG3 are also critical regulators of endocrine cell fate in the pancreas $[26,39]$. NEUROD1 levels were significantly increased in islets from patients with severe pancreatitis, whereas, as expected, NEUROG3 levels were low in adult cells.

In conclusion, humans with chronic severe pancreatitis demonstrated an increased number of single beta cells, an increased islet beta cell replication rate, and increased islet NEUROD1 levels. Despite these alterations, total beta cell number, fractional insulin area and apoptosis rate were similar to those in the other study groups. We believe these data are important for ongoing efforts seeking to convey human beta cell regeneration in vivo. While these current studies certainly provide clues as to the nature of cytokineinduced beta cell proliferation, future studies would be aided by the inclusion of additional patients, freshly obtained specimens and the inclusion of additional immunological (e.g. monitors of lymphoid and myeloid phenotype, cytokine production, apoptosis) and developmental (e.g. nestin) markers. Indeed, if the specific factors that mediate beta cell replication induced by chronic pancreatitis can be identified, this knowledge could assist the development of therapeutic strategies aimed at restoring beta cell mass in settings of insulin deficiency.

Acknowledgements These studies were funded by the National Institutes of Health (PO1 42288), Juvenile Diabetes Research Foundation, Sebastian and Keene Family Endowments, and Department of Pathology Clinical Research funds. We are grateful to $\mathrm{M}$. Chen, E. Gayle, and L. Tenace (Department of Pathology, University of Florida) for providing excellent technical support.

Duality of interest J. M. Crawford serves on the Medical Advisory Board for Aperio. The authors otherwise declare that there is no duality of interest associated with this manuscript.

\section{References}

1. Atkinson MA, Rhodes CJ (2005) Pancreatic regeneration in type 1 diabetes: dreams on a deserted islet. Diabetologia 48:2200-2202

2. Meier JJ, Bhushan A, Butler AE, Rizza RA, Butler PC (2005) Sustained beta cell apoptosis in patients with long-standing type 1 diabetes: indirect evidence for islet regeneration. Diabetologia 48:2221-2228

3. Bonner-Weir S, Weir GC (2005) New sources of pancreatic betacells. Nat Biotechnol 23:857-861

4. Bouwens L (2006) Beta cell regeneration. Curr Diabetes Rev 2:3-9

5. Lipsett M, Aikin R, Hanley S, Al-Maleek J, Laganiere S, Rosenburg L (2006) Islet neogenesis: a potential therapeutic tool in type 1 diabetes. Int J Biochem Cell Biol 38:715-720

6. Nir T, Melton DA, Dor Y (2007) Recovery from diabetes in mice by beta cell regeneration. J Clin Invest 117:2553-2561

7. Bonner-Weir S, Sharma A (2006) Are there pancreatic progenitor cells from which new islets form after birth. Nat Clinical Pract 2:240-241

8. Menge BA, Tannapfel A, Belyaev O et al (2008) Partial pancreatectomy in adult humans does not provoke beta-cell regeneration. Diabetes 57:142-149

9. Baeyens L, De Breuck S, Lardon J, Mfopou JK, Rooman I, Bouwens L (2005) In vitro generation of insulin-producing beta cells from adult exocrine pancreatic cells. Diabetologia 48:49-57

10. Yang L, Li S, Hatch $\mathrm{H}$ et al (2002) In vitro trans-differentiation of adult hepatic stem cells into pancreatic endocrine hormoneproducing cells. Proc Natl Acad Sci U S A 99:8078-8083

11. Butler AE, Huang A, Rao PN et al (2007) Hematopoietic stem cells derived from adult donors are not a source of pancreatic betacells in adult nondiabetic humans. Diabetes 56:1810-1816

12. Brand SJ, Tagerud S, Lambert $P$ et al (2002) Pharmacological treatment of chronic diabetes by stimulating pancreatic beta-cell regeneration with systemic co-administration of EGF and gastrin. Pharmacol Toxicol 91:414-420

13. Suarez-Pinzon WL, Yan Y, Power R, Brand SJ, Rabinovitch A (2005) Combination therapy with epidermal growth factor and gastrin increases beta-cell mass and reverses hyperglycemia in diabetic NOD mice. Diabetes 54:2596-2601

14. Tomassetti P, Migliori M, Lalli S, Campana D, Tomassetti V, Corinaldesi R (2001) Epidemiology, clinical features and diagnosis of gastroenteropancreatic endocrine tumours. Ann Oncol 12 (Suppl 2):S95-S99

15. Meier JJ, Butler AE, Galasso R, Rizza RA, Butler PC (2006) Increased islet beta cell replication adjacent to intrapancreatic gastrinomas in humans. Diabetologia 49:2689-2696

16. Jones EM, Sarvetnick N (1997) Islet regeneration in IFN $\gamma$ transgenic mice. Horm Metab Res 29:308-310 
17. Luo X, Yang H, Kim IS et al (2005) Systemic transforming growth factor- $\beta 1$ gene therapy induces Foxp $3+$ regulatory cells, restores self-tolerance, and facilitates regeneration of beta cell function in overtly diabetic nonobese diabetic mice. Transplantation 79:1091-1096

18. Maedler K, Schumann DM, Sauter N et al (2006) Low concentration of interleukin-1 $\beta$ induces FLICE-inhibitory protein-mediated beta-cell proliferation in human pancreatic islets. Diabetes 55:2713-2722

19. Smith U (2007) Introduction: symposium on diabetes, inflammation and cardiovascular disease. J Intern Med 262:142-144

20. Phillips JM, O'Reilly L, Bland C, Foulis AK, Cooke A (2007) Patients with chronic pancreatitis have islet progenitor cells in their ducts, but reversal of overt diabetes in NOD mice by anti-CD3 shows no evidence for islet regeneration. Diabetes 56:634-640

21. Meier JJ, Butler AE, Saisho Y et al (2008) Beta-cell replication is the primary mechanism subserving the postnatal expansion of beta-cell mass in humans. Diabetes 57:1584-1594

22. Sumi S, Gu Y, Hiura A, Inoue K (2004) Stem cells and regenerative medicine for diabetes mellitus. Pancreas 29:e85-e89

23. Zhang YQ, Sarvetnick N (2003) Development of cell markers for the identification and expansion of islet progenitor cells. Diabet Metab Res Rev 19:363-374

24. Zhang B, Lu Y, Campbell-Thompson M et al (2007) $\alpha 1$ Antitrypsin protects $\beta$-cells from apoptosis. Diabetes 56:13161323

25. Baggio LL, Drucker DJ (2006) Therapeutic approaches to preserve islet mass in type 2 diabetes. Annu Rev Med 57:265-281

26. Bouwens L, Rooman I (2005) Regulation of pancreatic beta-cell mass. Physiol Rev 85:1255-1270

27. Butler AE, Janson J, Bonner-Weir S, Ritzel R, Rizza RA, Butler PC (2003) Beta-cell deficit and increased beta-cell apoptosis in humans with type 2 diabetes. Diabetes 52:102-110
28. In’t Veld P, Lievens D, De Grijse J et al (2007) Screening for insulitis in adult autoantibody-positive organ donors. Diabetes 56:2400-2404

29. Greider MH, McGuigan JE (1971) Cellular localization of gastrin in the human pancreas. Diabetes 20:387-396

30. Rehfeld JF, Friis-Hansen L, Goetze JP, Hansen TV (2007) The biology of cholecystokinin and gastrin peptides. Current Topics in Medicinal Chemistry 7:1154-1165

31. Dockray G, Dimaline R, Varro A (2005) Gastrin: old hormone, new functions. Pflugers Arch 449:344-355

32. Meier JJ, Lin JC, Butler AE, Galasso R, Martinez DS, Butler PC (2006) Direct evidence of attempted beta cell regeneration in an 89 -year-old patient with recent-onset type 1 diabetes. Diabetologia 49:1838-1844

33. Katsumichi I, Pour PM (2007) Diabetes mellitus in pancreatic cancer: is it a causal relationship. Am J Surg 194:S71-S75

34. Schmied BM, Ulrich AB, Friess H, Buchler MW, Pour PM (2001) The patterns of extrainsular endocrine cells in pancreatic cancer. Teratog Carcinog Mutagen 21:69-81

35. Parnaud G, Bosco D, Berney T et al (2008) Proliferation of sorted human and rat beta cells. Diabetologia 51:91-100

36. Kassem SA, Ariel I, Thornton PS, Scheimberg I, Glaser B (2000) Beta-cell proliferation and apoptosis in the developing normal human pancreas and in hyperinsulinism of infancy. Diabetes 49:1325-1333

37. Gianani R, Putnam A, Still T et al (2006) Initial results of screening of nondiabetic organ donors for expression of islet autoantibodies. J Clin Endocrinol Metab 91:1855-1861

38. Fellous TG, Guppy NJ, Brittan M, Alison MR (2007) Cellular pathways to beta-cell replacement. Diabetes Metab Res Rev 23:87-99

39. Mellitzer G, Martin M, Sidhoum-Jenny M et al (2004) Pancreatic islet progenitor cells in neurogenin 3-yellow fluorescent protein knock-add-on mice. Mol Endocrinol 18:2765-2776 